\title{
Novel Insights Into Refugia at the Southern Margin of the Distribution Range of the Endangered Species Ulmus laevis
}

\begin{abstract}
Sara Torre ${ }^{1 \dagger}$, Federico Sebastiani ${ }^{* \dagger}$, Guia Burbui ${ }^{1}$, Francesco Pecori', Alessia L. Pepori', lacopo Passeri' ${ }^{1}$, Luisa Ghelardini ${ }^{2}$, Alberto Selvaggi ${ }^{3}$ and Alberto Santini ${ }^{1}$
\end{abstract}

${ }^{1}$ Istituto per la Protezione Sostenibile delle Piante, IPSP-CNR, Florence, Italy, ${ }^{2}$ Dipartimento di Scienze e Tecnologie Agrarie, Alimentari Ambientali e Forestali (DAGRI), Università di Firenze, Florence, Italy, ${ }^{3}$ Istituto per le Piante da Legno e l'Ambiente I.P.L.A. S.P.A., Turin, Italy

OPEN ACCESS

Edited by:

Andrew A. Crowl

Duke University, United States

Reviewed by:

Aziz Ebrahimi,

Purdue University, United States

An Vanden Broeck,

Research Institute for Nature and Forest (INBO), Belgium

*Correspondence:

Federico Sebastian

federico.sebastiani@ipsp.cnr.it

tThese authors have contributed equally to this work and share first authorship

Specialty section:

This article was submitted to Plant Systematics and Evolution,

a section of the journal

Frontiers in Plant Science

Received: 30 November 2021

Accepted: 14 January 2022

Published: 15 February 2022

Citation:

Torre S, Sebastiani F, Burbui G,

Pecori F, Pepori AL, Passeri I, Ghelardini L, Selvaggi $A$ and Santini $A$

(2022) Novel Insights Into Refugia

at the Southern Margin of the Distribution Range of the Endangered

Species UImus laevis.

Front. Plant Sci. 13:826158.

doi: 10.3389/fpls.2022.826158
Riparian ecosystems, in long-time developed regions, are among the most heavily impacted by human activities; therefore, the distribution of tree riparian species, such as Ulmus laevis, is highly affected. This phenomenon is particularly relevant at the margins of the natural habitat of the species, where populations are small and rare. In these cases, it is difficult to distinguish between relics or introductions, but it is relevant for the restoration of natural habitats and conservation strategies. The aim of this study was to study the phylogeography of the southern distribution of the species. We sequenced the entire chloroplast (cp) genomes of 54 individuals from five sampled populations across different European regions to highlight polymorphisms and analyze their distribution. Thirty-two haplotypes were identified. All the sampled populations showed private haplotypes that can be considered an indicator of longterm residency, given the low mutation rate of organellar DNA. The network of all haplotypes showed a star-like topology, and Serbian haplotypes were present in all branches. The Balkan population showed the highest level of nucleotide and genetic diversity. Low genetic differentiation between populations was observed but we found a significant differentiation among Serbia vs. other provenances. Our estimates of divergent time of $U$. laevis samples highlight the early split of above all Serbian individuals from other populations, emphasizing the reservoir role of white elm genetic diversity of Serbian population.

Keywords: conservation genetics, phylogeography, Ulmus laevis, plastome sequencing, forest trees, refugia, genetic polymorphisms

\section{INTRODUCTION}

Modern biodiversity conservation strategies rely, or at least should, on the knowledge of genetic resources (Gepts, 2006; Hoban et al., 2021). Big efforts were made in the exploration of genetic resources in the last decades (Halewood et al., 2018). In Europe, several foundation works were conducted on plant and animal organisms (Toro and Caballero, 2005; Koskela et al., 2013; 
Porth and El-Kassaby, 2014), exploring the geographical distribution and structure of genetic diversity and describing the patterns of reduction and expansion of populations mainly related to glaciation and recolonization, respectively (Petit et al., 2003; Heuertz et al., 2004; Mona et al., 2010; Lanier et al., 2015). In forest tree species, three main glacial refugia were identified in southern Europe, corresponding to the Iberian, Italian, and Balkan Peninsulas (Brewer et al., 2002; Heuertz et al., 2004; Magri et al., 2006), and post-glacial colonization routes of temperate species were hypothesized toward central and northern Europe (Petit et al., 2002; Magri, 2008). As a result of the expansion, a reduction in genetic diversity was expected from south to north (Gugerli et al., 2009), and this was partially confirmed, since most divergent populations were found in the Mediterranean areas, but the highest level of genetic diversity was observed in central Europe where the genetic lineages from different refugia got admixture (Petit et al., 2003). The picture that came out progressively gained complexity by considering the effect of preglacial variation distribution (Magri, 2008) and the existence of extra-Mediterranean refugia (Pedreschi et al., 2019). Despite these huge efforts, there are still species that are highly impacted by anthropogenic activity and by pests whose distribution is poorly investigated and that could represent a priority for habitat restoration.

European white elm (EWE) (Ulmus laevis Pall. = Ulmus effusa Willd. = Ulmus pedunculata Foug.) is a characteristic deciduous temperate forest tree species growing in river margins and lowland moist forests, and it can also tolerate dry soils of wooded steppe habitat in the central parts of the distribution. Seeds are generally anemochorous, but in the riparian habitats, hydrochory is an important means of transport, enabling long-distance dispersal (Vakkari et al., 2009). EWE is the only representative of the section Blepharocarpus in the Old World. U. laevis does not hybridize with other European species, namely, Ulmus glabra and Ulmus minor (Mittempergher and La Porta, 1991). Natural distribution range of EWE is mainly central and east European. It extends from Ural Mountains in the east to France in the west and from southern Finland in the north to Bosnia in the south (Svejgaard Jensen, 2003). There are even a few relict populations in south-western France (Timbal and Collin, 1999). Quite recently, some native relic scattered populations have been identified in the Iberian Peninsula (Fuentes-Utrilla et al., 2014). In Italy, it is generally considered allochthonous, naturalized in most regions (Pignatti et al., 2017) except in Piedmont (northwest) where it is considered native cryptogenic (Bartolucci et al., 2018) or native (Pignatti et al., 2017), in accordance with the hypothesis supported by regional botanic knowledge.

Elms in Europe are severely damaged by successive epidemic waves of Dutch elm disease (DED), a lethal disease caused by some non-native species of the genus Ophiostoma, namely, Ophiostoma ulmi, and Ophiostoma novo-ulmi ssp. novo-ulmi and O. novo-ulmi ssp. americana (Brasier, 2000). U. laevis is susceptible to the fungal agent of DED (O. novo-ulmi) (Santini et al., 2005), but it is able to avoid infections since it is far less attractive for the elm bark beetles, the main vector of the disease, than U. minor (Sacchetti et al., 1990). It is seldom attacked once other species are not present in an infested area anymore. Then, if the insect vectors do not change their feeding preferences, the genetic resources of $U$. laevis are not really endangered by DED (Collin, 2002). EWE populations are much more threatened by habitat destruction. Riparian forests, where EWE can be commonly found, are the sites of several human activities, namely, continuous cut for preventing floods, drained for reclaiming land for agriculture, and occasionally invaded by alien-human-introduced invasive plants. Therefore, the long-term survival of $U$. laevis throughout most of its distribution has been compromised (Franke et al., 2004). This has induced the generation of many small, isolated populations that result in vulnerability to genetic drift (Fuentes-Utrilla et al., 2014). In western Europe, the appropriate habitat for the species has been greatly reduced, although some small, isolated populations survive.

Typically, only populations that are recognized as native are included in the conservation process, while those that are considered introduced or have an uncertain status are not protected, which are excluded from regional Red Lists of the International Union for Conservation of Nature, even if they are rare and endangered (Decocq et al., 2004). The genetic tools used in most population genetic studies were based on different nuclear and molecular markers, mainly microsatellites (Morgante et al., 1996; Porth and El-Kassaby, 2014). The advent of high throughput sequencing offers from a few years the opportunity to explore genetic diversity at an unprecedented scale by sequencing portions to entire genomes and revealing unexplored genetic variation (Wang et al., 2001; Unamba et al., 2015; Ebrahimi et al., 2021).

Previous phylogeographic analyses in the genus Ulmus were based predominantly on neutral markers (Venturas et al., 2013; Zuo et al., 2020; Tamošaitis et al., 2021). In particular, the analysis of chloroplast (cp) markers in EWE populations (Whiteley, 2004) showed only three haplotypes, emphasizing the importance of exploring the entire genome. In recent years, the plastome analysis has facilitated molecular evolutionary studies because of its predominantly uniparental inheritance, small size, and slow nucleotide mutation rates (Wolfe et al., 1987), supplying the appropriate resolution frame to study plant phylogeography at deeper levels (Gitzendanner et al., 2018; Niu et al., 2018). Previous data on EWE genotyping highlighted the need to fill the gap on the southeast distribution of the species (Whiteley, 2004; Fuentes-Utrilla et al., 2014), even more so after the recent finding of an EWE stand in Italy, which was previously excluded from the natural distribution range. This work attempts to use whole plastid genome sequencing to better understand the phylogeography of $U$. laevis populations. The analysis of Serbian samples is critical to confirm the Balkans as the refugial origin of European populations.

Here, we aim to (a) explore the genetic structure of $U$. laevis at the south-western margin of its European distribution, (b) investigate whether Italian stands of white elms are natural or the result of anthropogenic introductions, and (c) discuss, in the light of new outcomes, the consequences for conservation and management strategies for this species. 


\section{MATERIALS AND METHODS}

\section{Plant Material and DNA Extraction}

The samples of $U$. laevis were collected in four areas and included in the natural range of the species: two in France (southwest and northeast), one in Spain, and one in Serbia. ${ }^{1}$ In addition, U. laevis samples were collected in northwestern Italy (Supplementary Table 1). Total genomic DNA was extracted from the leaves of each plant using the Invisorb Spin Plant Mini Kit (Invitek) following the instructions of the manufacturer.

\section{Plastome Sequencing and Assembly}

Using a genome skimming approach, all the samples were subjected to DNA shotgun sequencing. Genomic libraries were prepared and sequenced in paired-end mode $(2 \times 150$ bp reads $)$ on an Illumina HiSeq 4000 platform (Novogene Co., Ltd., Beijing, China). Illumina reads were trimmed using Trimmomatic (Bolger et al., 2014) with the following options: trailing: 10, leading: 10, sliding window: 4:20, seed mismatches: 2; palindrome clip threshold: 30, simple clip threshold: 10, and minlen: 40 . Clean reads of sample U1 (Supplementary Table 1) were used to assemble the cp genome of $U$. laevis using Novoplasty version 3.7 (Dierckxsens et al., 2017) with that of the congeneric species Ulmus pumila as reference (Zuo et al., 2017) and the following options: k-mer: 39 and seed: rbcL U. laevis. The software Snippy version 3.2- $\mathrm{dev}^{2}$ was used for reference-based mapping, consensus generation, and variant detection of all other samples. Gene annotation of plastomes was performed with GeSeq (Tillich et al., 2017) and BLAST (Altschul et al., 1990) analysis. The physical map of the $U$. laevis plastid genome was drawn with OGDRAW (Greiner et al., 2019).

\section{Characterization of cpDNA Polymorphisms, Haplotypic Network, and Genomic Diversity Analyses}

Plastid sequences were aligned using MAFFT version 7 (Katoh and Standley, 2013), and the resulting alignment was revised manually using CLC Genomics Workbench version 8.5.1 (Qiagen Aarhus, Denmark). Haplotypes were defined as combinations of single nucleotide polymorphism (SNP) and indel (insertiondeletion) variants across the $\mathrm{cp}$ genomes. The estimates of haplotype and nucleotide diversity were performed with DnaSP version 6 (Rozas et al., 2017) and PEGAS (Paradis et al., 2015) in R 4.0.4 (R Core Team, 2021). GenoDive version 3.05 (Meirmans and Van Tienderen, 2004) was used to calculate genetic diversity indices. To estimate the relationships between haplotypes, a minimum spanning network of haplotype was constructed using PEGAS by considering all mutation events, both SNPs and indels. Population differentiation based on cpDNA haplotypes was evaluated using two parameters, $G_{\mathrm{ST}}$ and $N_{\mathrm{ST}}$ (PERMUT 2.0; Pons and Petit, 1996); the presence of phylogeographic structure is highlighted when significantly greater values of $N_{S T}$ (that

${ }^{1}$ http://www.euforgen.org/species/ulmus-laevis/

${ }^{2}$ https://github.com/tseemann/snippy consider relatedness of haplotypes) in comparison with $G_{S T}$ (that measure the only frequency of haplotypes) are obtained.

A hierarchical analysis of molecular variance (AMOVA; Excoffier et al., 1992) was evaluated using GenAlEx version 6.5 software (Peakall and Smouse, 2012): the molecular variance $\left(\Phi_{\mathrm{PT}}\right.$, an analog of $\left.F_{\mathrm{ST}}\right)$ subdivided into variation among populations and among individuals within populations was evaluated by a permutation test $(n=999)$. The software GenAlEx was used to perform principal coordinates analysis (PCoA), and then plotted in R with the package ggplot2 (Wickham, 2016).

The geographical structure of haplotype diversity was tested with a Bayesian approach implemented in BAPS 6.0 (Corander et al., 2008) using the "clustering with linked loci" analysis. We applied a spatial genetic mixture analysis to the predefined groups of individuals. The software uses Markov chain Monte Carlo (MCMC) simulation to group the sampled populations into $\mathrm{K}$ clusters predefined by the user, and the best partitioning is attained based on the highest marginal log-likelihood. After the testing stage, the final analysis was conducted for 10 replicates for $\mathrm{K}$ ranging from 2 to 10 . Another clustering analysis was conducted by using the "Bayesian approach to phylogeographic clustering" (BPEC) package (Manolopoulou et al., 2016) implemented in $\mathrm{R}$ to verify the geographical structure of the populations and the most likely ancestral geographical locations. The analyses were conducted on a twodimensional dataset (i.e., longitude and latitude), with three levels of parsimony relaxation ( $\mathrm{d} s=0, \mathrm{ds}=1$, and $\mathrm{ds}=2$ ), allowing 5 migration events. Two MCMC chains were run for 100 million iterations.

\section{Phylogenetic Analysis of Ulmus laevis Populations and Estimation of Divergence Time}

The cpDNA sequences of $54 \mathrm{U}$. laevis individuals and 13 plant species within the family Ulmaceae as outgroups (e.g., ten Ulmus species, two Zelkova species, and one Hemiptelea species) were aligned using MAFFT version 7.308 (Katoh and Standley, 2013). We created a time-calibrated phylogenetic tree, reconstructing the phylogeographical relationships and calculating the divergence time of $U$. laevis populations. The plastome phylogeny was inferred by applying the Bayesian inference (BI) method using the program BEAST2 version 2.6.3.0 (Bouckaert et al., 2014). The transversion model (TMV) substitution model was determined to be the best substitution model using a hierarchical likelihood ratio test framework as implemented in jModeltest version 2.1.10 (Darriba et al., 2012). After preliminary runs, we selected the best prior settings for various parameters to achieve an improved effective sample size (ESS) value. We used the lognormal relaxed molecular clock approach and assumed a Yule process of speciation, setting the parameters in BEAUti. The following five priors with normal distribution were selected for calibrations from published data (Zhang et al., 2021): (1) we constrained the crown age of the lineage Ulmaceae to be 85.39 million years ago (Mya) (sigma 1.0, offset: 0.0); (2) Ulmus clade was set to 52 Mya (sigma 1.0, offset: 0.0); (3) crown age of Zelkova was constrained to be 54.53 
Mya (sigma 1.0, offset: 0.0); (4) crown age of Hemiptelea was set to 72.59 Mya (sigma 1.0, offset: 0.0); and (5) split between Ulmus americana and U. laevis was constrained to 17.5 Mya. The Bayesian posterior probabilities were sampled using the MCMC algorithm, which was run for $3.0 \times 10^{8}$ generations and sampled every 1,000 . The stationarity of the chains and convergence of MCMC simulations were monitored using Tracer version 1.7.1 (Rambaut et al., 2018), analyzing the log output of the BEAST2 analysis. ESSs of all parameters were more than 200, indicating that the estimations were confident. After stationarity was obtained, a maximum clade credibility (MCC) tree was generated using TreeAnnotator version 2.6.3.0 (Helfrich et al., 2019), setting the $20 \%$ of trees discarded as burn-in. The MCC tree was visualized using FigTree version 1.4.4 and then was plotted with a geological timescale using the strap package in $\mathrm{R}$ (Bell and Lloyd, 2015).

\section{Effective Population Size $\left(\mathbf{N}_{e}\right)$}

We estimated the effective population size $\left(N_{e}\right)$ through time for the five populations, applying a non-parametric analysis based on the coalescence theory to cpDNA genome alignments for each population separately. The Bayesian skyline plot (BSP) approach was employed with the TMV substitution site model using a relaxed lognormal molecular clock with rate 1.0 and running $3.0 \times 10^{8}$ MCMC simulations using the software BEAST2.

\section{RESULTS}

\section{Ulmus laevis Chloroplast Genome}

The complete nucleotide sequence of the cp genome of $U$. laevis was determined through HTS "skim sequencing" (Kumar et al., 2021). Using 864,534 high-quality plastid reads, the cpDNA of one individual (Fsw1) was de novo assembled with a depth coverage of $815 \times$. The cpDNA had a size of $159,086 \mathrm{bp}$, had a guanine-cytosine (GC) content of $35.6 \%$, and its map had the typical quadripartite structure of angiosperms, including two inverted repeats (IRs) of 26,424 bp separated by a large single copy (LSC) of $87,594 \mathrm{bp}$ and a small single copy (SSC) of $18,644 \mathrm{bp}$ (Figure 1). The cp genome of $U$. laevis encodes 120 unique genes, of which 19 are duplicated in the IR, giving a total of 139 genes (Table 1). The Fsw1 cpDNA was used to map the sequencing reads (ranging from 88,686 to 322,795) of 55 other U. laevis samples with an average depth coverage of $304 \times$.

The entire $\mathrm{cp}$ genomes of the 56 samples were aligned and haplotypes were identified. The dataset was then reduced to 54 cp genomes: samples U29 and U35 (Supplementary Table 1) were the same sample sequenced twice as well as sample U42 was sequenced twice as control for the sequencing process, as expected we obtained the same haplotypes from replicated samples. Only unique samples were kept for further analysis. The 54 plastomes were deposited in GenBank under the accession number PRJNA777116.

\section{Genetic Diversity and Population Differentiation}

The alignment of the $54 \mathrm{cp}$ genomes highlighted 190 nucleotide polymorphisms (14 SNPs and 176 indels). Most of the polymorphisms were neutral, and only 14 of these variations (6 SNPs and 8 indels) were in annotated regions. We found 3 mutations (SNPs) into coding sequences, 2 causing synonymous mutations (in psaB and psaI genes, respectively, both involved in Photosystem I), and 1 non-synonymous mutation in the rpoC1 gene (that catalyzes a DNA-directed RNA polymerase).

All the polymorphisms allowed identifying 32 haplotypes (Supplementary Table 2). Twenty-four haplotypes were private, only 8 haplotypes were represented by more than one sample, and the most frequent haplotype included 11 samples (Table 2). The effective number of haplotypes varied across the four populations from 3.6 (France_SW) to 12.0 (Serbia). Haplotypic richness was close to the average for all four populations, ranging from 3.0 (France_SW) to 3.848 (Serbia). Private haplotypes were present in all five populations. The sequencing of the entire plastid genomes unveiled a high number of haplotypes that was reflected in high values of haplotypic diversity: total haplotype diversity was 0.945 and varied from 1.0 (Serbia, France_NE) to 0.801 (Italy). Interestingly, among other polymorphisms, we recovered a 7 bp insertion (TAATAAA) already described in the study by Fuentes-Utrilla et al. (2014) in 5 out of 10 Spain samples and 1 sample from France_SW. Overall nucleotide diversity $\left(\pi=1.028 \times 10^{-5}\right)$ was low and ranged from the higher value $2.439 \times 10^{-5}$ in Serbia to 0 in Spain, where all variants were indels. A comparison of diversity indices obtained with SNPs and indels is reported in Supplementary Table 3.

The median-joining network of all haplotypes (Figure 2) showed a star-like topology consisting of a central haplotype (I) from which most of the other haplotypes radiated and separated usually by one to two mutations. Serbian haplotypes were present all over the network, close to the center but also with the most diverging haplotypes (XIX, XX).

Total genetic diversity was high $\left(H_{T}=0.960\right)$, but the largest part of cpDNA variation was found within the populations $\left(H_{S}=0.922\right)$. The analyzed $U$. laevis populations showed the low levels of population differentiation $\left(G_{S T}=0.050\right)$. Low but significant differentiation was observed among the pairs Italy-Serbia, Spain-Serbia, and Spain-Italy (Table 3). In addition, the AMOVA showed that the differences among populations explained $31 \%$ of the total variation, while most of the variance $(71 \%)$ was located within populations (data not shown).

The PCoA scatterplot of the $54 \mathrm{cp}$ genomes is presented in Figure 3. The first two PCoA axes account for about $76 \%$ of the total variation in the cpDNA, revealing a clear clustering in three groups with multiple haplotypes. The group at the extreme right of the first axis included only Serbian haplotypes. In addition to the three groups, another sample from Serbia (Se14) was resolved.

Using the Bayesian methods, optimum genetic clusters $(k=4)$ were obtained, which did not correspond to the populations. The analysis with BAPS did not display a strong genetic structure along the western part of the sampled species distribution, and two major clusters contained individuals from all four populations (i.e., Spain, France_SW, France_NE, and Italy); nevertheless, two clusters were represented only in Serbia: one with few individuals and the other one included only one individual (Figure 4A). 


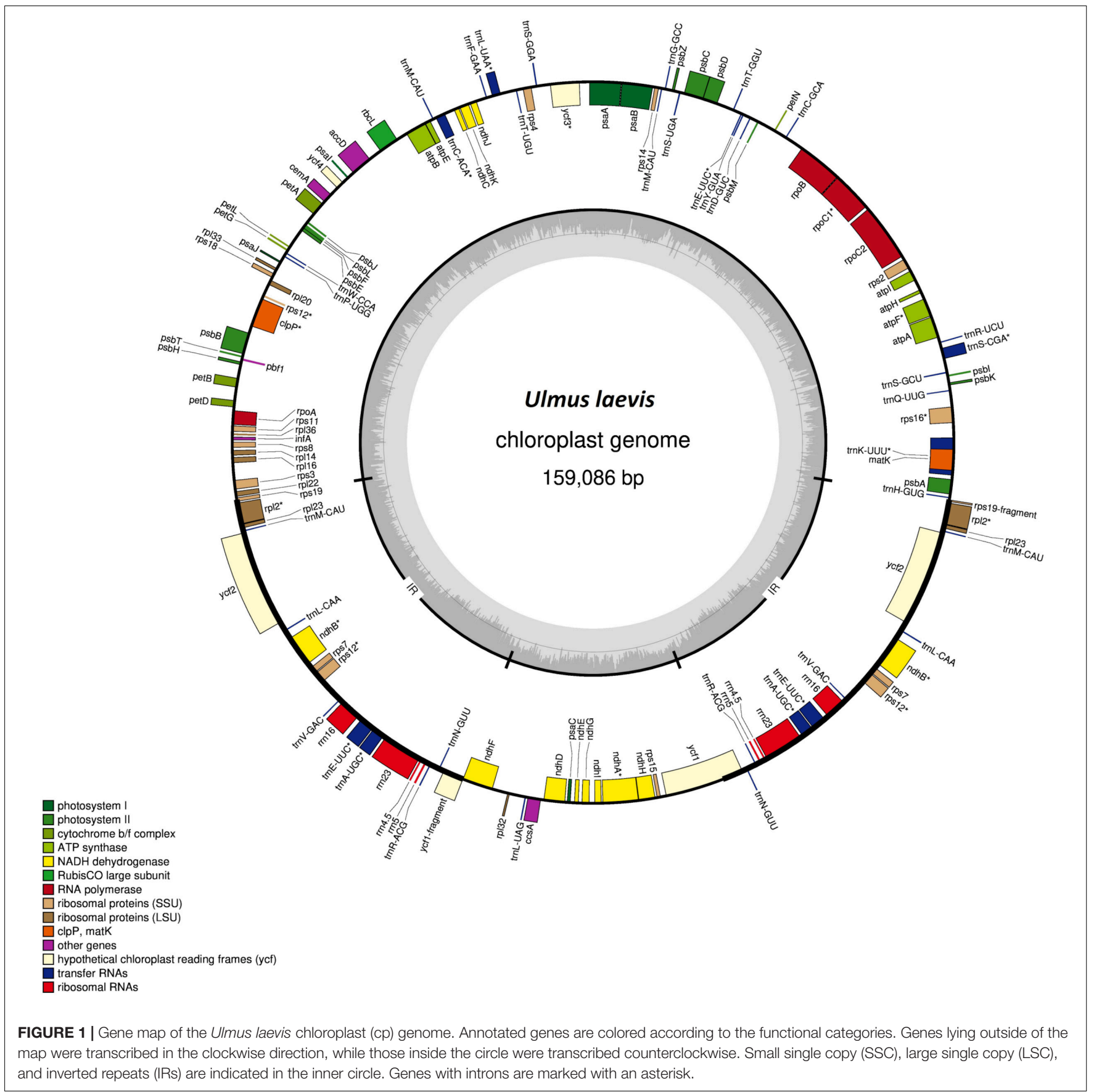

The BPEC clustering showed high uncertainty about the location and number of clusters in the assignment of plastid haplotypes, except for Serbian individuals (Figure 4B): haplotypes were assigned to "Serbian" phylogeographic cluster with generally high posterior probabilities $(0.64-0.98)$. The most likely ancestral locations corresponded to sites located in the Ticino valley.

\section{Molecular Dating}

The Bayesian phylogenetic inference of cpDNA haplotypes subdivided populations into two main clades, one associated with almost all samples from Serbian populations (Se14, Se15, Se23, Se16, Se22, Se18, and Se24; clade I) and another one composed of other samples (clade II) (Figure 5). The molecular dating analysis suggested that the two clades diverged during the Upper Miocene, 17.3 Mya ago [95\% highest posterior density (HPD): 12.9-18.7]. Lineages from the Serbian region constituting clade I show more recent allelic divergence, in the range of 5.1-10.1 Mya (95\% HPD: 0-6.2 and 3.8-16.7, respectively). In clade I, the Se14 sample started diverging before the others, exhibiting greater genetic differentiation, as confirmed by the other analyses. Regarding clade II, it is noteworthy a subclade including five 
TABLE 1 | List of genes present in the Ulmus laevis chloroplast genome.

\begin{tabular}{|c|c|c|}
\hline Category & Group of genes & Name of genes \\
\hline \multirow[t]{5}{*}{ Self-replication } & Large subunit of ribosomal protein & rpl2, 14, 16, 20, 22, 23, 32, 33, 36 \\
\hline & Small subunit of ribosomal proteins & rps2, 3, 4, 7, 8, 11, 12, 14, 15, 16, 18, 19 \\
\hline & DNA dependent RNA polymerase & rрoA, B, C1, C2 \\
\hline & rRNA genes & rRNA 16S, 23S, 4.5S, $5 S$ \\
\hline & tRNA genes & 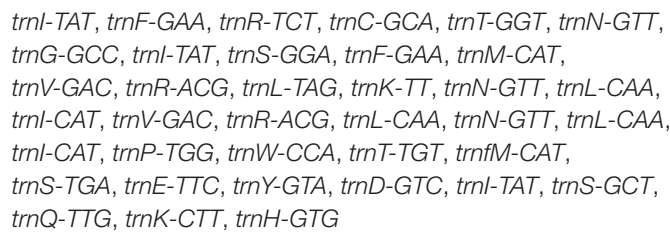 \\
\hline \multirow[t]{7}{*}{ Photosynthesis } & Photosystem I & psaA, B, C, I, J \\
\hline & Photosystem II & $p s b A, B, C, D, E, F, H, I, J, K, L, M, T, Z$ \\
\hline & Photosystem biogenesis & $p b f 1$ \\
\hline & $\mathrm{NadH}$ oxidoreductase & $n d h A, B, C, D, E, F, G, H, I, J, K$ \\
\hline & Cytochrome b6/f complex & $\operatorname{pet} A, B, D, G, L, N$ \\
\hline & ATP synthase & $\operatorname{atp} A, B, E, F, H, l$ \\
\hline & Rubisco & $r b c L$ \\
\hline \multirow[t]{6}{*}{ Other genes } & Maturase & matk \\
\hline & Protease & clpP \\
\hline & Envelop membrane protein & cemA \\
\hline & Subunit Acetyl-CoA-Carboxylate & $a c c D$ \\
\hline & c-type cytochrome synthesis gene & $\operatorname{ccs} A$ \\
\hline & Translation initiation factor IF-1 & $\operatorname{infA}$ \\
\hline Unknown & Conserved open reading frames & $y c f 1,2,3,4$ \\
\hline
\end{tabular}

samples (i.e., It42, Fsw3, It38, Fsw1, and It37) from Italian and French_SW populations that also show a relatively recent divergence time, from 4.9 to 5.96 Mya (95\% HPD: 0.01-6.1 and $0.1-8.0$, respectively). Among all 13 outgroups, Hemiptelea was confirmed to be the most genetically divergent, and this is consistent with earlier studies (Ueda et al., 1997; Sytsma et al., 2002; Zhang et al., 2021), being a sister of the Ulmus and Zelkova genera.

Profiles for the effective population size $\left(N_{e}\right)$ are shown in the four Skyline plots in Figure 6 (it was not possible to calculate a Skyline plot for the Spanish population due to the lack of informative variations). The BSPs suggest that the median estimate of population size of all four European populations remained constant throughout the time. Only the Serbian population revealed a quite small increase in the

TABLE 2 | Sample size in each population (N), number of haplotypes detected in each population $(A)$, number of private haplotypes $(P)$, effective number of haplotypes (N_e), and genetic diversity suggested by Nei (1987) corrected for sample size (hapDiv) and nucleotide diversity (nucDiv) in chloroplast DNA sequences of Ulmus laevis populations.

\begin{tabular}{lcccccc}
\hline Population & N & A & P & N_e & hapDiv & nucDiv \\
\hline France_SW & 5 & 4 & 2 & 3.6 & 0.900 & $6.286 \mathrm{e}-06$ \\
France_NE & 8 & 8 & 6 & 8.0 & 1.000 & $3.143 \mathrm{e}-06$ \\
Serbia & 12 & 12 & 10 & 12.0 & 1.000 & $2.439 \mathrm{e}-05$ \\
Italy & 19 & 9 & 5 & 4.1 & 0.801 & $1.764 \mathrm{e}-06$ \\
Spain & 10 & 6 & 5 & 5.5 & 0.911 & $\mathrm{NA}$
\end{tabular}

effective population size $\left(N_{e}\right)$ just after the coalescence, while no significant changes in $N_{e}$ were observed in the other populations. French (NE and SW) and Italian populations share a stable ancestral size.

\section{DISCUSSION}

This study sought to explore the genetic structure of the species $U$. laevis in the southern part of its distribution range. Two main focuses were identified, namely, (i) the unexplored glacial refugium in the Balkan Peninsula and (ii) whether small Italian stands in the north-west (Piedmont and Ticino valley) are relic native ones or allochthonous.

This study is among the first to use large-scale intraspecific plastome sequencing of a European forest tree species to explore genetic diversity at population level. The plastid genome of U. laevis was recently sequenced (Zhang et al., 2021), but this study provides the first complete annotated plastid genome of EWE and the assessment of intraspecific diversity together with the elucidation of the phylogeography of this species in its southern European range. The cp markers have long been used in forest tree population genetics but were often limited to few polymorphic loci (Scotti et al., 2008; Bagnoli et al., 2009; Dias et al., 2020). The cpDNA sequences of U. laevis were highly conserved in terms of size, gene number, and arrangement; however, the full cpDNA sequencing of $U$. laevis unveiled unexplored genetic variation. In fact, 190 polymorphic sites were 


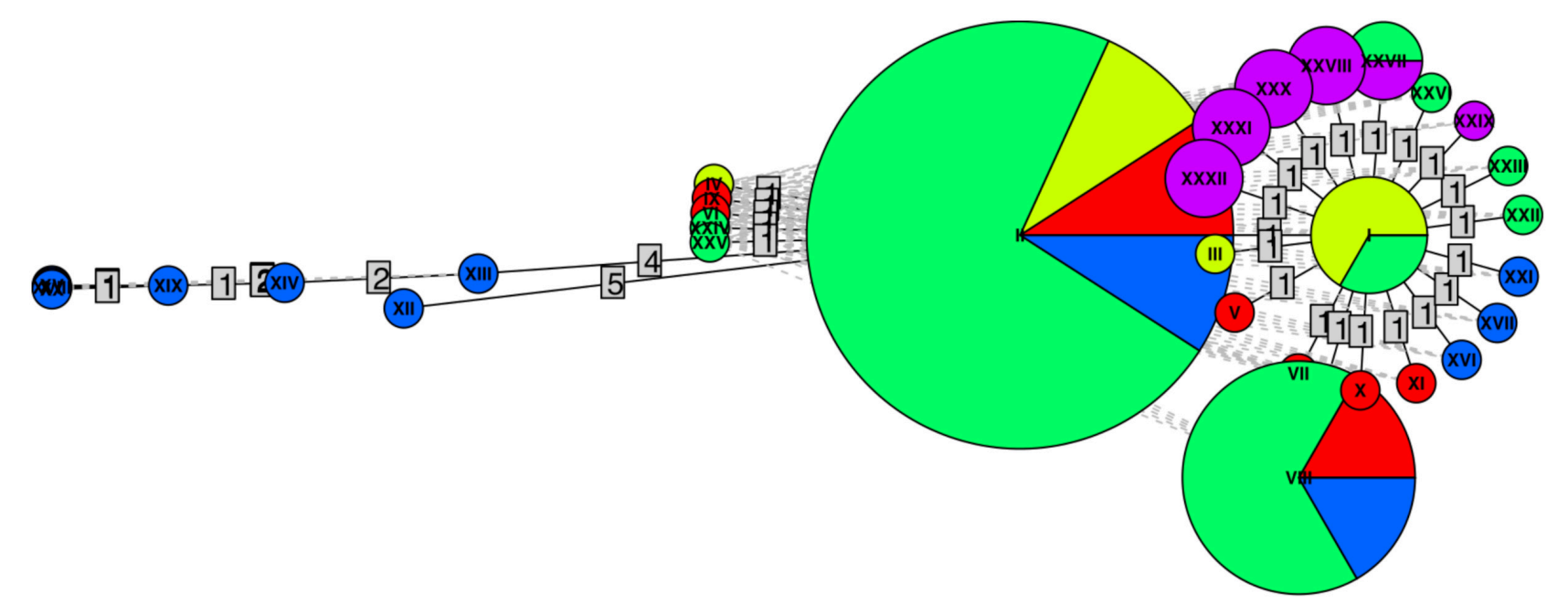

FIGURE 2 | Haplotype network of the 32 UImus laevis haplotypes computed using R package "pegas." Circles are colored according to the provenance of haplotype from different geographic areas. The size of the circles is proportional to the frequencies of each haplotype across all populations. Lines represent the mutational steps between haplotype sequences.

identified that gave rise to 32 haplotypes, and all the sampled populations showed private haplotypes.

Paleobotanical records witnessed the presence of Ulmus spp. in Italy (Mercuri et al., 2002; Amorosi et al., 2014) but, unfortunately, these reports cannot shed light on the past white elm distribution in Italy because, so far, it is not possible to distinguish Ulmus species. Our estimates of divergent time of $U$. laevis samples highlight that a subset of Serbian individuals started diverging from the Upper Miocene, while another subset formed a clade with all other provenances. Considering that this approach produces values regarding allelic divergence, while the species are always more recent, our tree is consistent with the

TABLE 3 | Values of GST suggested by Nei (1987) for all pairs of populations below the diagonal and $N_{\mathrm{ST}}$ above.

\begin{tabular}{lccccc}
\hline & France_SW & France_NE & Serbia & Italy & Spain \\
\hline France_SW & - & 0.008 & 0.308 & -0.061 & 0.012 \\
France_NE & 0.023 & - & $0.353^{\star}$ & -0.033 & $0.346^{\star}$ \\
Serbia & 0.030 & -0.021 & - & $0.351^{*}$ & $0.339^{*}$ \\
Italy & 0.054 & 0.027 & 0.049 & - & 0.311 \\
Spain & 0.094 & 0.045 & 0.044 & 0.139 & - \\
All samples GST & 0.034 & & & & \\
All samples NST & 0.078 & & & & \\
\hline
\end{tabular}

Tests of phylogeographical signal (i.e., $N_{S T}>G_{S T}$ ): ${ }^{*} p<0.05$. divergent times calculated for the other Ulmaceae species (Zhang et al., 2017; Hou et al., 2020). The early split of above all Serbian individuals from other populations combined with the diversity that cluster I samples exhibit in more recent times highlights the role of the Serbian population as a reservoir for EWE genetic diversity and main source for recolonization. At the same time, the more recent divergence exhibited by samples from Italy and southwest France could suggest their long-term refugia isolation.

Considering that the mutation rate of organellar DNA is remarkably low (the mutation rate of cpDNA is in the order of $1.3 \times 10^{-9}$ ) (Wolfe et al., 1987), private haplotypes (P) can be considered an indicator of long-term residency which makes anthropogenic introductions unlikely (Wares et al., 2002). Interestingly, the higher number of $P$, as well as the highest effective number of haplotypes, was observed in Serbia. Nevertheless, private haplotypes were found also in all other areas, though at reduced frequency.

The high number of private haplotypes is reflected in the haplotype network that, alongside the star-like structure, has many tips. The central haplotype, haplotype I, common to France_SW and Italy, should represent the most ancient condition, according to the coalescent theory (Castelloe and Templeton, 1994), while more recently derived haplotypes should be at the tips. According to Posada and Crandall (2001), the haplotypic structure would predict Italy and France_SW as potential refugia but most of the haplotypes are close to 


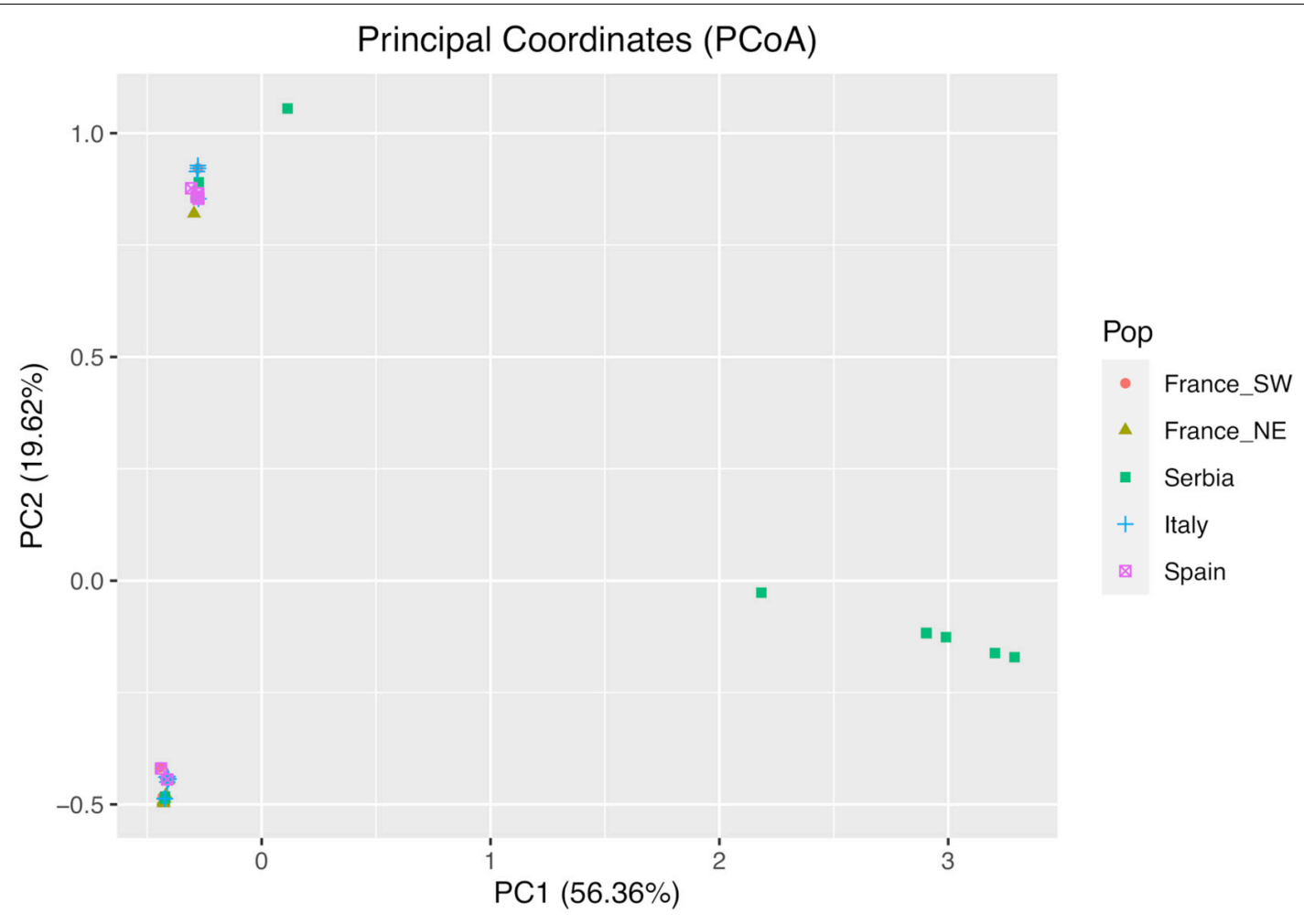

FIGURE 3 | Principal coordinates analysis (PCOA) showing variation between the 54 chloroplast (cp) genomes. Each point represents a haplotype. Geographical regions are marked by different colors.
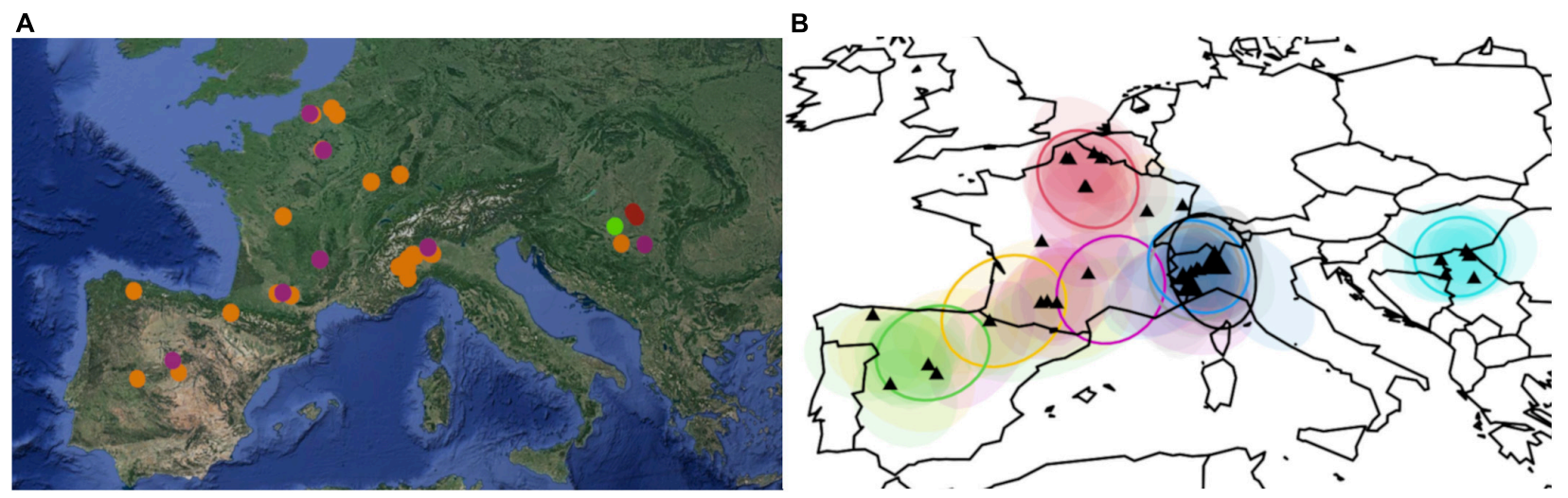

FIGURE 4 | (A) Map showing the location of the four genetic clusters identified by Bayesian analysis of population structure (BAPS) for $k=4$, using the spatial model. Chart was generated by PhyloGeoViz (Tsai, 2011). Terrain image copyright by Google Earth. The colors represent the cluster to which the analyzed individuals belong based on BAPS assignment. (B) Cluster analysis built by the Bayesian phylogeographic and ecological clustering. Each colored areas indicate a different phylogeographic grouping.

haplotype I, differing for just one mutation; hence, this structure is not so strong. In fact, the haplotypes found in the Serbian population are distributed over the entire network, from close derivatives of ancestral haplotypes to most distant, and their frequent appearance is remarkable and in agreement with a long-term occurrence.

Genetic diversity among and within populations is expected to be higher in refugia than in recently colonized areas. Plant populations in refugia are recognized as those that exhibit high levels of genetic diversity and uniqueness (Petit et al., 2003; Carnaval et al., 2009). Haplotype diversity is high in all samples, but interestingly, Serbian population has higher nucleotide diversity $(\pi=2.439 \mathrm{e}-05)$. Thus, higher genetic diversity evidenced by the Serbian population could reflect the accumulation of nucleotide mutations that characterize the isolation of individuals belonging to a refugia population. 


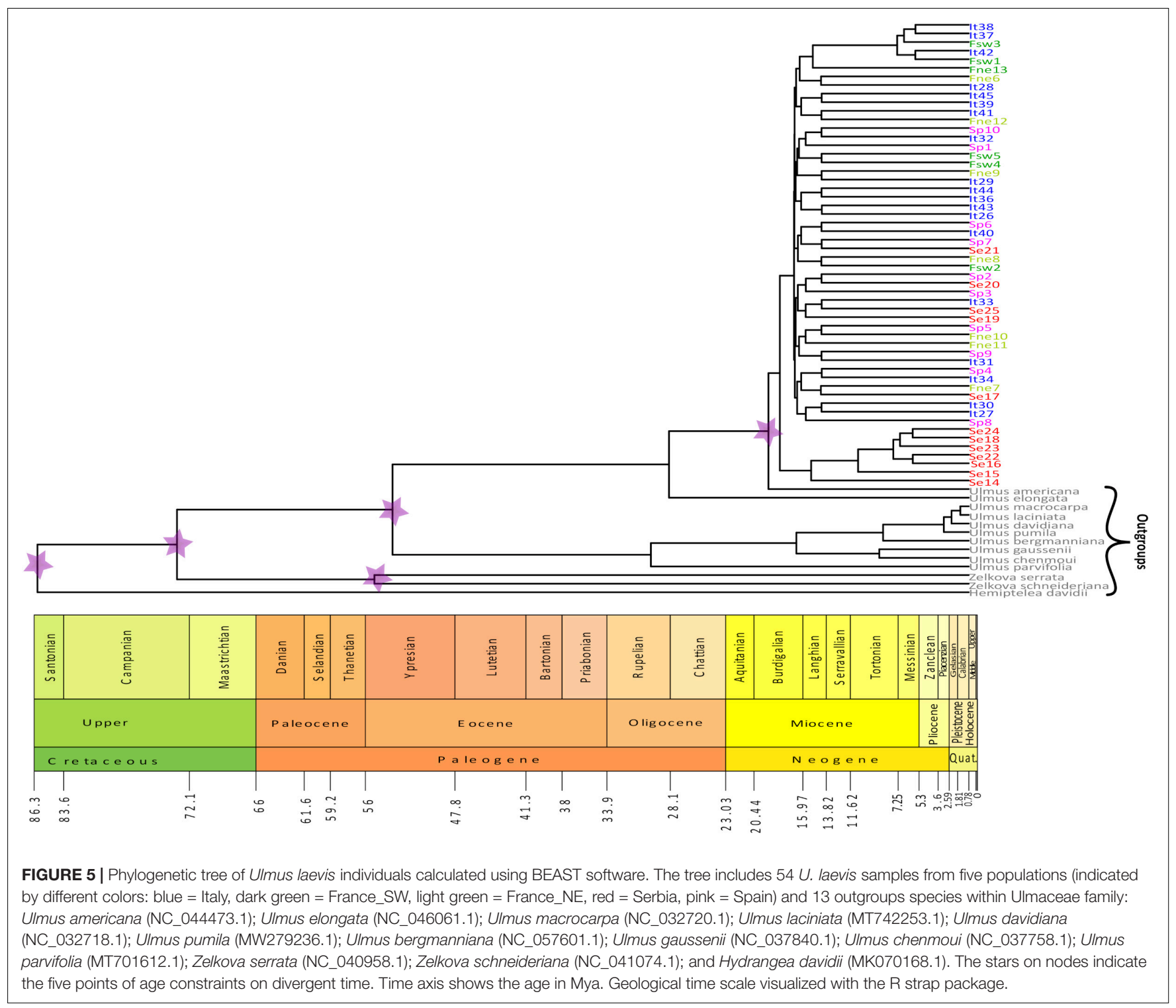

The Balkan Peninsula might have provided suitable habitat for U. laevis during the Pleistocene climate oscillations. Multiple refugia have been inferred in the Balkan Peninsula for many animals and plants during the Pleistocene glacial periods (Ursenbacher et al., 2008; Bagnoli et al., 2016).

Our phylogeographic survey showed a low genetic differentiation due to the high level of haplotype diversity found within populations. Overall, $N_{S T}$ was not significantly higher than $G_{S T}$; however, no negligible phylogeographic signal was detected in pairwise comparisons. In fact, $N_{S T}$ of Serbian samples was significantly higher than $G_{S T}$ of samples from Italy, Spain, and France_NE.

The Bayesian genetic clustering identified four groups, all of which present in Serbia, while only two were detected in the other sampled areas; these data together with the results of PCoA highlight the Balkan area as the one of the greatest diversity, which is possibly the main refuge area for the species. The confirmed absence of a clear structure is particularly significant considering the use of uniparentally inherited genetic markers. In contrast, the weak genetic structure within regions can be explained by a high rate of seed dispersal and long-range colonization of plastome variants (maternally inherited with seeds), while the overall observed genetic structuring could be originated by the accumulation of mutations in different refugia followed by recent population expansion. Consistent with these observations are the results of BSPs used for inference of coalescence patterns (Heller et al., 2013), which indicate a peculiarity of Serbian individuals attributable to the glacial refuge condition.

According to Fuentes-Utrilla et al. (2014), Spain can be considered a potential refuge, but in this view, Italy emerged as a previously unrecognized native population. If the appearance of new alleles following introductions can be ruled out because of the very low mutation rate and then two alternative hypotheses 


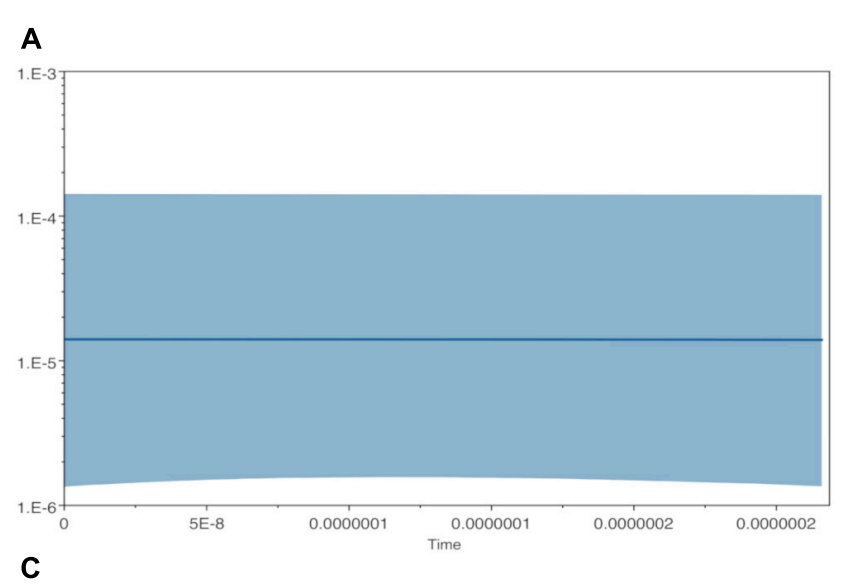

\section{B}
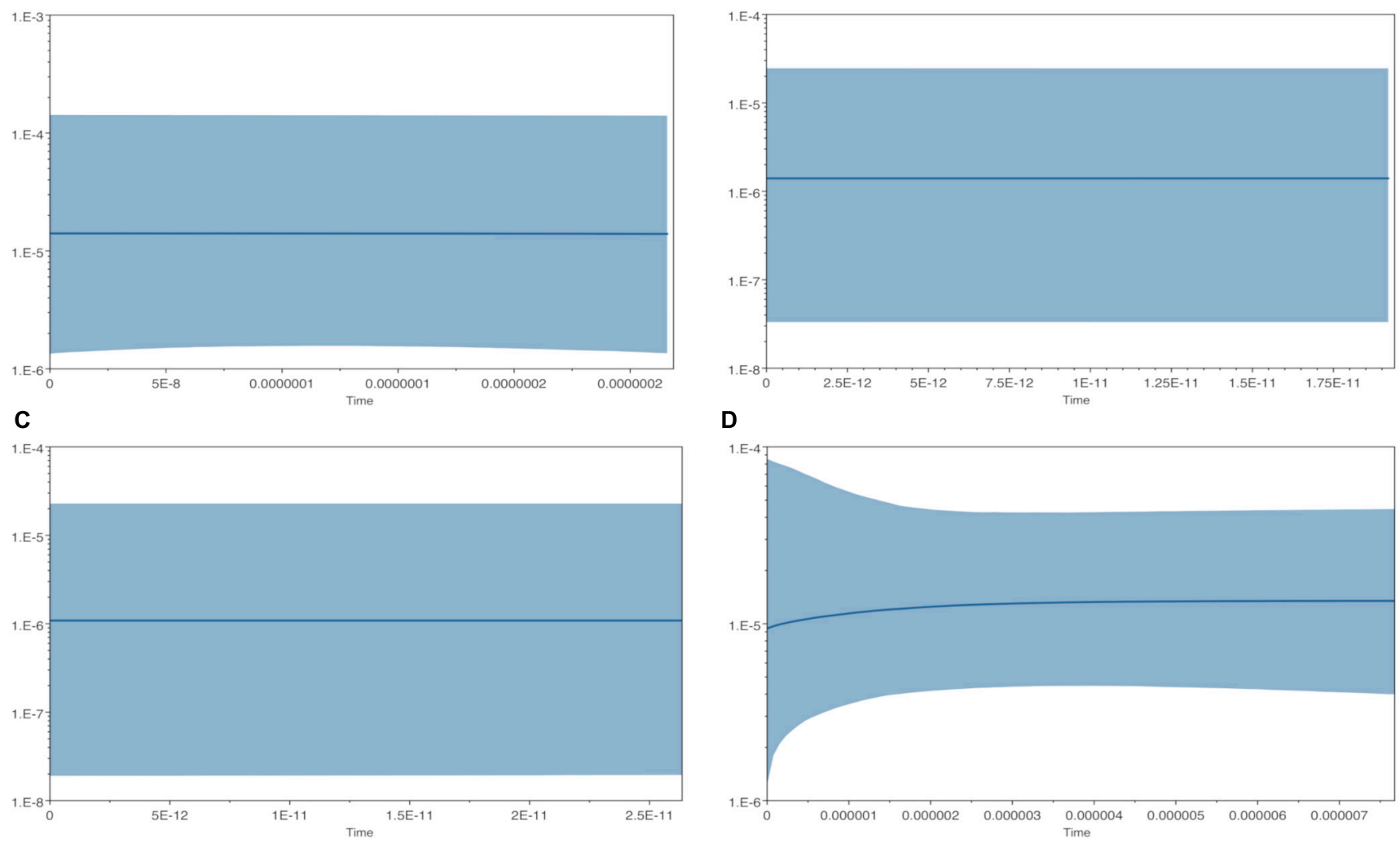

FIGURE 6 | Bayesian Skyline plots derived from cpDNA sequences of Ulmus laevis. The analysis was performed for each population separately. The $X$-axis is in units of million years ago (Mya) and the $Y$-axis is the population size, expressed in units of Ne $\tau$, the product of effective population sizes per generation length. The thick solid line represents the mean effective population size $N_{e}$, while the $95 \%$ highest posterior density (HPD) limits are shown by the blue area. (A) France_NE, (B) France_SW, (C) Italy, and (D) Serbia.

can be formulated, namely, the first one is that the observed data are the product of multiple introductions, but the sampling was not adequate to highlight the source; alternatively, we are observing the results of a composite demographic history, with small/cryptic refugia scattered at the margins of actual species distribution contributing to the actual diversity of haplotypes. Although we are dealing with a small-scale sample size, it was established that this should not interfere with the estimates of patterns of genetic diversity at a wide geographical range (Taberlet et al., 2012). Overall, the observed pattern of diversity could be explained with the existence of a principal refuge in the Balkans that represented the main source of postglacial colonization from southeast to central and northern Europe. Based on our results, mainly the presence of private haplotypes, the Italian population may no longer be considered an anthropogenic introduction, but could be considered native and, consistently, with previous study for French (Timbal and Collin, 1999) and Spanish populations (Fuentes-Utrilla et al., 2014), all most likely originated from Serbian refuge.

Although the connection with Balkan refugia still needs deeper investigation, unfortunately, there are no warnings about the presence of white elms on the northeastern part of Italy, but long-range dispersal cannot be ruled out.
In support of our hypothesis, there are also arguments linked to the ecology of the species and the habitat transformation: most of the sampled trees were at the margin of high intensively cultivated areas close to rivers or scattered not far from such small stands. The area where we hypothesized a native presence of white elms, on the western side of the Po valley, experienced a high rate of population growth since the Neolithic Age. During the Roman Age, an extensive deforestation occurred, due to the assignment of land grants to war veterans, and continued in different ways till nowadays (Marchetti, 2002). The prolonged human presence highly impacted natural ecosystems by mainly extending urbanization and cultivated areas of agricultural crop. In that context, the introduction of white elms, species with no great economical relevance, especially at the bottom of the Alps, has no reasonable explanations. The Italian EWE population, which is conserving an important amount of genetic diversity, is composed of small, scattered populations at the margin of the distribution of species, and this pattern is in line with the evolution of the territory. Continued anthropogenic action along river courses could further limit the current populations, putting them at risk of extinction. This risk is a call for the maintenance of evolutionary processes through the conservation of genetic resources. Riparian forests, in whose ecosystem the EWE is 
a distinctive species, have high biodiversity and an important ecological role, so any change in their ecological dynamics also impacts the population dynamics of trees and, thus, their genetic diversity (Guilloy-Froget et al., 2002). For this reason, the conservation of genetic resources should be done with a dynamic approach not only at the level of single species but also on the whole riparian ecosystem (Lefèvre et al., 2013).

The pattern of genetic diversity observed in U. laevis is largely congruent with other previously studied European species, such as Hordelymus europaeus and Fagus sylvatica and another riparian tree, Alnus glutinosa (Magri, 2008; Dvořková et al., 2010; Havrdová et al., 2015); in particular, it points to the existence of a main refugium in the Balkan Peninsula, while additional southern refugial rear-edge populations in Iberian and Italian Peninsulas represent current the relicts with unique haplotype diversity.

Although more intensive sampling of the European populations in combination with nuclear genotyping is needed to give a more complete picture of the phylogeography of U. laevis, this study, to the best of our knowledge, for the first time extended the population genetic analysis of EWE to Italian and Balkan populations, revealing probably the main refuge of the species during the last glaciation. In addition, we extended the natural range of $U$. laevis in Europe to northwestern Italy and highlighted their small size and fragmentation and also at risk. The risk comes more from population size and habitat erosion than from DED; anyway, proper management practices become important to preserve these small stands with both in situ and ex situ actions to preserve and hopefully restore riparian ecosystems.

\section{DATA AVAILABILITY STATEMENT}

The datasets presented in this study can be found in online repositories. The name of the repository and accession number can be found below: https://www.ncbi.nlm.nih.gov/ genbank/, PRJNA777116.

\section{REFERENCES}

Altschul, S. F., Gish, W., Miller, W., Myers, E. W., and Lipman, D. J. (1990). Basic local alignment search tool. J. Mol. Biol. 215, 403-410. doi: 10.1016/S00222836(05)80360-2

Amorosi, A., Antonioli, F., Bertini, A., Marabini, S., Mastronuzzi, G., Montagna, P., et al. (2014). The middle-upper pleistocene fronte section (Taranto, Italy): an exceptionally preserved marine record of the Last Interglacial. Glob. Planet. Change 119, 23-38. doi: 10.1016/J.GLOPLACHA.2014.04.007

Bagnoli, F., Tsuda, Y., Fineschi, S., Bruschi, P., Magri, D., Zhelev, P., et al. (2016). Combining molecular and fossil data to infer demographic history of Quercus cerris: insights on European eastern glacial refugia. J. Biogeogr. 43, 679-690. doi: 10.1111/JBI.12673

Bagnoli, F., Vendramin, G. G., Buonamici, A., Doulis, A. G., GonzÁlez-MartÍnez, S. C., La Porta, N., et al. (2009). Is Cupressus sempervirens native in Italy? An answer from genetic and palaeobotanical data. Mol. Ecol. 18, 2276-2286. doi: 10.1111/j.1365-294X.2009.04182.x

Bartolucci, F., Peruzzi, L., Galasso, G., Albano, A., Alessandrini, A., Ardenghi, N. M. G., et al. (2018). An updated checklist of the vascular flora native to Italy. Plant Biosyst. 152, 179-303. doi: 10.1080/11263504.2017.1419996

\section{AUTHOR CONTRIBUTIONS}

FS and ASa conceived the study. ST, FS, IP, and AP conducted all laboratory and population genetics analyses. GB, FP, ASa, LG, and ASe collected the samples. ST and FS led the writing of the manuscript. All authors contributed to the article and approved the submitted version.

\section{FUNDING}

This research has received funding from the Parco Lombardo della Valle del Ticino and ERSAF (Ente Regionale per i Servizi all'Agricoltura e alle Foreste) Lombardia.

\section{ACKNOWLEDGMENTS}

We thank Eric Collin (IRSTEA, France) and Martin Venturas (E.T.S.I. Montes, Universidad Politécnica de Madrid, Spain) for providing samples from France and Spain, respectively; we also thank Paolo Varese, Andrea Ebone, and Gian Paolo Mondino for sharing their distribution knowledge on EWE in Piedmont. This article is dedicated to the memory of Nenad Keca, Sumarski fakultet Univerziteta $\mathrm{u}$ Beogradu, a friend and an esteemed colleague. Nenad sampled Ulmus laevis in Serbia and, with his help, it was possible to shed light on the phylogeography of EWE.

\section{SUPPLEMENTARY MATERIAL}

The Supplementary Material for this article can be found online at: https://www.frontiersin.org/articles/10.3389/fpls.2022. 826158/full\#supplementary-material

Bell, M. A., and Lloyd, G. T. (2015). strap: an R package for plotting phylogenies against stratigraphy and assessing their stratigraphic congruence. Palaeontology 58, 379-389. doi: 10.1111/PALA.12142

Bolger, A. M., Lohse, M., and Usadel, B. (2014). Trimmomatic: a flexible trimmer for Illumina sequence data. Bioinformatics 30, 2114-2120. doi: 10. 1093/bioinformatics/btu170

Bouckaert, R., Heled, J., Kühnert, D., Vaughan, T., Wu, C.-H., Xie, D., et al. (2014). BEAST 2: a software platform for bayesian evolutionary analysis. PLoS Comput. Biol. 10:e1003537. doi: 10.1371/JOURNAL.PCBI.100 3537

Brasier, C. M. (2000). "Intercontinental spread and continuing evolution of the Dutch Elm disease pathogens," in The Elms, ed. C. P. Dunn (Boston, MA: Springer), 61-72. doi: 10.1007/978-1-4615-4507-1_4

Brewer, S., Cheddadi, R., de Beaulieu, J. L., Reille, M., Allen, J., Almqvist-Jacobson, H., et al. (2002). The spread of deciduous Quercus throughout Europe since the last glacial period. For. Ecol. Manag. 156, 27-48. doi: 10.1016/S0378-1127(01) 00646-6

Carnaval, A. C., Hickerson, M. J., Haddad, C. F. B., Rodrigues, M. T., and Moritz, C. (2009). Stability predicts genetic diversity in the brazilian atlantic forest hotspot. Science 323, 785-789. doi: 10.1126/SCIENCE.1166955 
Castelloe, J., and Templeton, A. R. (1994). Root probabilities for intraspecific gene trees under neutral coalescent theory. Mol. Phylogenet. Evol. 3, 102-113. doi: 10.1006/MPEV.1994.1013

Collin, E. (2002). Strategies and Guidelines for the Conservation of the Genetic Resources of Ulmus spp. 50-67. Available online at: https://hal.inrae.fr/hal02580649 (accessed October 15, 2021).

Corander, J., Marttinen, P., Sirén, J., and Tang, J. (2008). Enhanced bayesian modelling in BAPS software for learning genetic structures of populations. BMC Bioinforma 91:539. doi: 10.1186/1471-2105-9-539

Darriba, D., Taboada, G. L., Doallo, R., and Posada, D. (2012). jModelTest 2: more models, new heuristics and parallel computing. Nat. Methods 98:772. doi: $10.1038 /$ nmeth.2109

Decocq, G., Bordier, D., Wattez, J.-R., and Racinet, P. (2004). A practical approach to assess the native status of a rare plant species: the controverse of Buxus sempervirens L. in northern France revisited. Plant Ecol. 1731, 139-151. doi: 10.1023/B:VEGE.0000026337.85794.FB

Dias, A., Giovannelli, G., Fady, B., Spanu, I., Vendramin, G. G., Bagnoli, F., et al. (2020). Portuguese Pinus nigra J.F. Arnold populations: genetic diversity, structure and relationships inferred by SSR markers. Ann. For. Sci. 773, 1-15. doi: 10.1007/S13595-020-00967-9

Dierckxsens, N., Mardulyn, P., and Smits, G. (2017). NOVOPlasty: de novo assembly of organelle genomes from whole genome data. Nucleic Acids Res. 45:e18. doi: 10.1093/nar/gkw955

Dvořková, H., Fér, T., and Marhold, K. (2010). Phylogeographic pattern of the European forest grass species Hordelymus europaeus: cpDNA evidence. Flora Morphol. Distrib. Funct. Ecol. Plants 205, 418-423. doi: 10.1016/J.FLORA.2009. 12.029

Ebrahimi, A., Antonides, J. D., Pinchot, C. C., Slavicek, J. M., Flower, C. E., and Woeste, K. E. (2021). The complete chloroplast genome sequence of American elm (Ulmus americana) and comparative genomics of related species. Tree Genet. Genomes 17, 1-13. doi: 10.1007/S11295-020-01487-3

Excoffier, L., Smouse, P. E., and Quattro, J. M. (1992). Analysis of molecular variance inferred from metric distances among DNA haplotypes: application to human mitochondrial DNA restriction data. Genetics 131, 479-491. doi: 10.1093/GENETICS/131.2.479

Franke, A., Gil, L., Rusanen, M., Aguiar, A., Collin, E., Harvengt, L., et al. (2004). Methods and progress in the conservation of elm genetic resources in Europe. Investig. Agrar. Sist. y Recur. For. 13, 261-272. doi: 10.5424/831

Fuentes-Utrilla, P., Venturas, M., Hollingsworth, P. M., Squirrell, J., Collada, C., Stone, G. N., et al. (2014). Extending glacial refugia for a European tree: genetic markers show that iberian populations of white elm are native relicts and not introductions. Heredity 112, 105-113. doi: 10.1038/hdy.2013.81

Gepts, P. (2006). Plant genetic resources conservation and utilization: the accomplishments and future of a societal insurance policy. Crop Sci. 46, 22782292. doi: 10.2135/CROPSCI2006.03.0169GAS

Gitzendanner, M. A., Soltis, P. S., Wong, G. K.-S., Ruhfel, B. R., and Soltis, D. E. (2018). Plastid phylogenomic analysis of green plants: a billion years of evolutionary history. Am. J. Bot. 105, 291-301. doi: 10.1002/AJB2.1048

Greiner, S., Lehwark, P., and Bock, R. (2019). OrganellarGenomeDRAW (OGDRAW) version 1.3.1: expanded toolkit for the graphical visualization of organellar genomes. Nucleic Acids Res. 47, W59-W64. doi: 10.1093/nar/gkz238

Gugerli, F., Rüegg, M., and Vendramin, G. G. (2009). Gradual decline in genetic diversity in Swiss stone pine populations (Pinus cembra) across Switzerland suggests postglacial re-colonization into the Alps from a common eastern glacial refugium. Bot. Helv. 119, 13-22. doi: 10.1007/s00035-009-0052-6

Guilloy-Froget, H., Muller, E., Barsoum, N., and Hughes, F. M. R. (2002). Dispersal, germination, and survival of populus nigra L. (salicaceae) in changing hydrologic conditions. Wetlands 22, 478-488.

Halewood, M., Chiurugwi, T., Hamilton, R. S., Kurtz, B., Marden, E., Welch, E., et al. (2018). Plant genetic resources for food and agriculture: opportunities and challenges emerging from the science and information technology revolution. New Phytol. 217, 1407-1419. doi: 10.1111/NPH.14993

Havrdová, A., Douda, J., Krak, K., Vít, P., Hadincová, V., Zákravský, P., et al. (2015). Higher genetic diversity in recolonized areas than in refugia of Alnus glutinosa triggered by continent-wide lineage admixture. Mol. Ecol. 24, 4759-4777. doi: 10.1111/MEC. 13348

Helfrich, P., Rieb, E., Abrami, G., Lücking, A., and Mehler, A. (2019). "Treeannotator: versatile visual annotation of hierarchical text relations," in LREC 2018 - 11th International Conference on Language Resources and Evaluation, Miyazaki, 1958-1963.

Heller, R., Chikhi, L., and Siegismund, H. R. (2013). The confounding effect of population structure on bayesian skyline plot inferences of demographic history. PLoS One 8:e62992. doi: 10.1371/JOURNAL.PONE.0062992

Heuertz, M., Fineschi, S., Anzidei, M., Pastorelli, R., Salvini, D., Paule, L., et al. (2004). Chloroplast DNA variation and postglacial recolonization of common ash (Fraxinus excelsior L.) in Europe. Mol. Ecol. 13, 3437-3452. doi: 10.1111/j. 1365-294X.2004.02333.x

Hoban, S., Campbell, C. D., da Silva, J. M., Ekblom, R., Funk, W. C., Garner, B. A., et al. (2021). Genetic diversity is considered important but interpreted narrowly in country reports to the convention on biological diversity: current actions and indicators are insufficient. Biol. Conserv. 261:109233. doi: 10.1016/J.BIOCON. 2021.109233

Hou, H., Ye, H., Wang, Z., Wu, J., Gao, Y., Han, W., et al. (2020). Demographic history and genetic differentiation of an endemic and endangered Ulmus lamellosa (Ulmus). BMC Plant Biol. 20:526. doi: 10.1186/s12870-020-02723-7

Katoh, K., and Standley, D. M. (2013). MAFFT multiple sequence alignment Software Version 7: improvements in performance and usability. Mol. Biol. Evol. 30, 772-780. doi: 10.1093/MOLBEV/MST010

Koskela, J., Lefèvre, F., Schueler, S., Kraigher, H., Olrik, D. C., Hubert, J., et al. (2013). Translating conservation genetics into management: pan-European minimum requirements for dynamic conservation units of forest tree genetic diversity. Biol. Conserv. 157, 39-49. doi: 10.1016/J.BIOCON.2012.07.023

Kumar, P., Choudhary, M., Jat, B. S., Kumar, B., Singh, V., Kumar, V., et al. (2021). Skim sequencing: an advanced NGS technology for crop improvement. J. Genet. 100:38. doi: 10.1007/S12041-021-01285-3

Lanier, H. C., Massatti, R., He, Q., Olson, L. E., and Knowles, L. L. (2015). Colonization from divergent ancestors: glaciation signatures on contemporary patterns of genomic variation in Collared Pikas (Ochotona collaris). Mol. Ecol. 24, 3688-3705. doi: 10.1111/MEC.13270

Lefèvre, F., Koskela, J., Hubert, J., Kraigher, H., Longauer, R., Olrik, D. C., et al. (2013). Dynamic conservation of forest genetic resources in 33 European Countries. Conserv. Biol. 27, 373-384. doi: 10.1111/j.1523-1739.2012.01961.x

Magri, D. (2008). Patterns of post-glacial spread and the extent of glacial refugia of European beech (Fagus sylvatica). J. Biogeogr. 35, 450-463. doi: 10.1111/J.13652699.2007.01803.X

Magri, D., Vendramin, G. G., Comps, B., Dupanloup, I., Geburek, T., Gömöry, D., et al. (2006). A new scenario for the quaternary history of European beech populations: palaeobotanical evidence and genetic consequences. New Phytol. 171, 199-221. doi: 10.1111/j.1469-8137.2006.01740.x

Manolopoulou, I., Hille, A., and Emerson, B. (2016). BPEC: an R package for bayesian phylogeographic and ecological clustering. J. Stat. Softw. 92, 1-32.

Marchetti, M. (2002). Environmental changes in the central Po Plain (northern Italy) due to fluvial modifications and anthropogenic activities. Geomorphology 44, 361-373. doi: 10.1016/S0169-555X(01)00183-0

Meirmans, P. G., and Van Tienderen, P. H. (2004). GENOTYPE and GENODIVE: two programs for the analysis of genetic diversity of asexual organisms. Mol. Ecol. Notes 4, 792-794. doi: 10.1111/j.1471-8286.2004.00770.x

Mercuri, A. M., Accorsi, C. A., and Bandini Mazzanti, M. (2002). The long history of Cannabis and its cultivation by the Romans in central Italy, shown by pollen records from Lago Albano and Lago di Nemi. Veg. Hist. Archaeobotany 114, 263-276. doi: 10.1007/S003340200039

Mittempergher, L., and La Porta, N. (1991). Hybridization studies in the Eurasian species of elm (Ulmus spp.). Silvae Genet. 40, 237-243.

Mona, S., Catalano, G., Lari, M., Larson, G., Boscato, P., Casoli, A., et al. (2010). Population dynamic of the extinct European aurochs: genetic evidence of a north-south differentiation pattern and no evidence of post-glacial expansion. BMC Evol. Biol. 10:83. doi: 10.1186/1471-2148-10-83

Morgante, M., Pfeiffer, A., Costacurta, A., and Olivieri, A. M. (1996). Molecular tools for population and ecological genetics in coniferous trees. Phyt. Ann. Rei Bot. 36, 129-138.

Nei, M. (1987). Molecular Evolutionary Genetics. New York, NY: Columbia University Press. doi: 10.7312/NEI-92038

Niu, Y. T., Ye, J. F., Zhang, J. L., Wan, J. Z., Yang, T., Wei, X. X., et al. (2018). Longdistance dispersal or postglacial contraction? Insights into disjunction between Himalaya-Hengduan Mountains and Taiwan in a cold-adapted herbaceous genus, Triplostegia. Ecol. Evol. 8, 1131-1146. doi: 10.1002/ece3.3719 
Paradis, E., Jombart, T., Schliep, K., Potts, A., Winter, D., and Paradis, M. E. (2015). Package "Pegas" Title Population and Evolutionary Genetics Analysis System.

Peakall, R., and Smouse, P. E. (2012). GenAlEx 6.5: genetic analysis in Excel. Population genetic software for teaching and research-an update. Bioinformatics 28, 2537-2539. doi: 10.1093/BIOINFORMATICS/BTS 460

Pedreschi, D., García-Rodríguez, O., Yannic, G., Cantarello, E., Diaz, A., Golicher, D., et al. (2019). Challenging the European southern refugium hypothesis: species-specific structures versus general patterns of genetic diversity and differentiation among small mammals. Glob. Ecol. Biogeogr. 28, 262-274. doi: 10.1111/GEB. 12828

Petit, R. J., Aguinagalde, I., De Beaulieu, J. L., Bittkau, C., Brewer, S., Cheddadi, R., et al. (2003). Glacial refugia: hotspots but not melting pots of genetic diversity. Science 300, 1563-1565. doi: 10.1126/science.1083264

Petit, R. J., Brewer, S., Bordács, S., Burg, K., Cheddadi, R., Coart, E., et al. (2002). Identification of refugia and post-glacial colonisation routes of European white oaks based on chloroplast DNA and fossil pollen evidence. For. Ecol. Manag. 156, 49-74. doi: 10.1016/S0378-1127(01)00634-X

Pignatti, S., Guarino, R., and La Rosa, M. (2017). Flora d'Italia, 2nd Edn, Vol. 1-4. Bologna: Edagricole.

Pons, O., and Petit, R. J. (1996). Measuring and testing genetic differentiation with ordered versus unordered alleles. Genetics 144, 1237-1245. doi: 10.1093/ genetics/144.3.1237

Porth, I., and El-Kassaby, Y. A. (2014). Assessment of the genetic diversity in forest tree populations using molecular markers. Divers 6, 283-295. doi: 10.3390/ D6020283

Posada, D., and Crandall, K. A. (2001). Intraspecific gene genealogies: trees grafting into networks. Trends Ecol. Evol. 16, 37-45. doi: 10.1016/S0169-5347(00)020267

R Core Team (2021). R: A Language and Environment for Statistical Computing. Vienna: R Foundation for Statistical Computing.

Rambaut, A., Drummond, A. J., Xie, D., Baele, G., and Suchard, M. A. (2018). Posterior summarization in bayesian phylogenetics using tracer 1.7. Syst. Biol. 67, 901-904. doi: 10.1093/SYSBIO/SYY032

Rozas, J., Ferrer-Mata, A., Sanchez-DelBarrio, J. C., Guirao-Rico, S., Librado, P., Ramos-Onsins, S. E., et al. (2017). DnaSP 6: DNA sequence polymorphism analysis of large data sets. Mol. Biol. Evol. 34, 3299-3302. doi: 10.1093/ MOLBEV/MSX248

Sacchetti, P., Tiberi, R., and Mittempergher, L. (1990). Preference of Scolytus multistriatus (Marsham) during the gonad maturation phase between two species of elm. Redia $73,347-354$.

Santini, A., Montaghi, A., Vendramin, G. G., and Capretti, P. (2005). Analysis of the Italian Dutch Elm disease fungal population. J. Phytopathol. 153, 73-79. doi: 10.1111/J.1439-0434.2004.00931.X

Scotti, I., Gugerli, F., Pastorelli, R., Sebastiani, F., and Vendramin, G. G. (2008). Maternally and paternally inherited molecular markers elucidate population patterns and inferred dispersal processes on a small scale within a subalpine stand of Norway spruce (Picea abies [L.] Karst.). For. Ecol. Manag. 255, 38063812. doi: 10.1016/J.FORECO.2008.03.023

Svejgaard Jensen, J. (2003). EUFORGEN Technical Guidelines for Genetic Conservation and use for Lime (Tilia spp.). Rome: IPGRI.

Sytsma, K. J., Morawetz, J., Chris Pires, J., Nepokroeff, M., Conti, E., Zjhra, M., et al. (2002). Urticalean rosids: circumscription, rosid ancestry, and phylogenetics based on rbcL, trnL-F, and ndhF sequences. Am. J. Bot. 89, 1531-1546. doi: 10.3732/ajb.89.9.1531

Taberlet, P., Zimmermann, N. E., Englisch, T., Tribsch, A., Holderegger, R., Alvarez, N., et al. (2012). Genetic diversity in widespread species is not congruent with species richness in alpine plant communities. Ecol. Lett. 15, 1439-1448. doi: 10.1111/ele.12004

Tamošaitis, S., Jurkšienè, G., Petrokas, R., Buchovska, J., Kavaliauskiene, I., Danusevičius, D., et al. (2021). Dissecting taxonomic variants within Ulmus spp. complex in natural forests with the aid of microsatellite and morphometric markers. For 12:653. doi: 10.3390/F12060653

Tillich, M., Lehwark, P., Pellizzer, T., Ulbricht-Jones, E. S., Fischer, A., Bock, R., et al. (2017). GeSeq - versatile and accurate annotation of organelle genomes. Nucleic Acids Res. 45, W6-W11. doi: 10.1093/NAR/GKX391

Timbal, J., and Collin, E. (1999). The Ulmus laevis Pallas in southern France distribution and strategy for genetic resource conservation. Fr. For. J. 51, 593-604. doi: 10.4267/2042/5468
Toro, M. A., and Caballero, A. (2005). Characterization and conservation of genetic diversity in subdivided populations. Philos. Trans. R. Soc. B Biol. Sci. 360, 1367-1378. doi: 10.1098/rstb.2005.1680

Tsai, Y. H. E. (2011). PhyloGeoViz: a web-based program that visualizes genetic data on maps. Mol. Ecol. Resour. 11, 557-561. doi: 10.1111/J.1755-0998.2010. 02964.X

Ueda, K., Kosuge, K., and Tobe, H. (1997). A molecular phylogeny of Celtidaceae and Ulmaceae (Urticales) based on rbcL nucleotide sequences. J. Plant Res. 110, 171-178. doi: 10.1007/bf02509305

Unamba, C. I. N., Nag, A., and Sharma, R. K. (2015). Next generation sequencing technologies: the doorway to the unexplored genomics of non-model plants. Front. Plant Sci. 6:1074. doi: 10.3389/fpls.2015.01074

Ursenbacher, S., Schweiger, S., Tomović, L., Crnobrnja-Isailović, J., Fumagalli, L., and Mayer, W. (2008). Molecular phylogeography of the nose-horned viper (Vipera ammodytes, Linnaeus (1758)): evidence for high genetic diversity and multiple refugia in the Balkan peninsula. Mol. Phylogenet. Evol. 46, 1116-1128. doi: 10.1016/J.YMPEV.2007.11.002

Vakkari, P., Rusanen, M., and Kärkkäinen, K. (2009). High genetic differentiation in marginal populations of European White Elm (Ulmus laevis). Silva Fenn. 43, 185-196. doi: 10.14214/SF.205

Venturas, M., Fuentes-Utrilla, P., Ennos, R., Collada, C., and Gil, L. (2013). Human-induced changes on fine-scale genetic structure in Ulmus laevis Pallas wetland forests at its SW distribution limit. Plant Ecol. 214, 317-327. doi: 10.1007/s11258-013-0170-5

Wang, X. R., Wang, X. R., and Szmidt, A. E. (2001). Molecular markers in population genetics of forest trees. Scand. J. For. Res. 16, 199-220. doi: 10.1080/ 02827580118146

Wares, J. P., Goldwater, D. S., Kong, B. Y., and Cunningham, C. W. (2002). Refuting a controversial case of a human-mediated marine species introduction. Ecol. Lett. 5, 577-584. doi: 10.1046/J.1461-0248.2002.00359.X

Whiteley, R. (2004). Quantitative and Molecular Genetic Variations in lemph\{Ulmus laevis\} Pall.

Wickham, H. (2016). ggplot2. doi: 10.1007/978-3-319-24277-4

Wolfe, K. H., Li, W. H., and Sharp, P. M. (1987). Rates of nucleotide substitution vary greatly among plant mitochondrial, chloroplast, and nuclear DNAs. Proc. Natl. Acad. Sci. U.S.A. 84, 9054-9058. doi: 10.1073/pnas.84.24.9054

Zhang, M. L., Wang, L., Lei, Y., and Sanderson, S. C. (2017). Cenozoic evolutionary history of Zelkova (Ulmaceae), evidenced from ITS, trnL-trnF, psbA-trnH, and rbcL. Tree Genet. Genomes 13, 1-10. doi: 10.1007/s11295-017-1182-4

Zhang, Q. Y., Deng, M., Bouchenak-Khelladi, Y., Zhou, Z. K., Hu, G. W., and Xing, Y.W. (2021). The diversification of the northern temperate woody flora - A case study of the Elm family (Ulmaceae) based on phylogenomic and paleobotanical evidence. J. Syst. Evol doi: 10.1111/jse.12720

Zuo, L., Zhang, S., Zhang, J., Liu, Y., Yu, X., Yang, M., et al. (2020). Primer development and functional classification of EST-SSR markers in Ulmus species. Tree Genet. Genomes 16:74. doi: 10.1007/S11295-020-01468-6

Zuo, L.-H., Shang, A.-Q., Zhang, S., Yu, X.-Y., Ren, Y.-C., Yang, M.-S., et al. (2017). The first complete chloroplast genome sequences of Ulmus species by de novo sequencing: genome comparative and taxonomic position analysis. PLoS One 12:e0171264. doi: 10.1371/JOURNAL.PONE.0171264

Conflict of Interest: The authors declare that the research was conducted in the absence of any commercial or financial relationships that could be construed as a potential conflict of interest.

Publisher's Note: All claims expressed in this article are solely those of the authors and do not necessarily represent those of their affiliated organizations, or those of the publisher, the editors and the reviewers. Any product that may be evaluated in this article, or claim that may be made by its manufacturer, is not guaranteed or endorsed by the publisher.

Copyright ๔ 2022 Torre, Sebastiani, Burbui, Pecori, Pepori, Passeri, Ghelardini, Selvaggi and Santini. This is an open-access article distributed under the terms of the Creative Commons Attribution License (CC BY). The use, distribution or reproduction in other forums is permitted, provided the original author(s) and the copyright owner(s) are credited and that the original publication in this journal is cited, in accordance with accepted academic practice. No use, distribution or reproduction is permitted which does not comply with these terms. 